\title{
ATUALIZANDO A QUÍMICA ORGÂNICA EXPERIMENTAL DA LICENCIATURA
}

Marcelo Navarro, Vera L. M. de Sena, Rajendra M. Srivastava e Daniela M. do Amaral Ferraz Navarro*

Departamento de Química Fundamental, Centro de Ciências Exatas e da Natureza, Universidade Federal de Pernambuco, Cidade Universitária, 50670-901 Recife - PE

Recebido em 1/9/04; aceito em 7/3/05; publicado na web em 11/7/05

\begin{abstract}
UPDATING UNDERGRADUATE EXPERIMENTAL ORGANIC CHEMISTRY. The present contribution describes three different modern experiments for possible adoption in undergraduate organic chemistry laboratories. These are: 1. electrocatalytic hydrogenation of benzaldehyde to benzyl alcohol; 2. identification of three volatile components, obtained from pineapple fruit, by mass spectrometry and 3. microwave mediated fast synthesis of $N$-( $p$-chlorophenyl)phthalamic acid from phthalic anhydride and $p$-chloroaniline under solvent-free conditions. The experiments can be executed in a short period of time, putting the undergraduate student in contact with a variety of topics in organic chemistry and several techniques of analysis, showing multidisciplinarity in organic chemistry.
\end{abstract}

Keywords: electrocatalytic hydrogenation; dynamic headspace analysis; solvent-free organic synthesis.

\section{INTRODUÇÃO}

Os profissionais da área de educação em Química têm suas atividades divididas em 3 categorias: instrução, prática e pesqui$\mathrm{sa}^{1}$. O ramo da instrução é familiar a todos. O ramo da prática envolve o desenvolvimento de ferramentas e métodos usados para ensinar Química. Incluem-se também aqueles que elaboram software, são autores de livros-texto, desenvolvem experimentos e aulas demonstrativas. O pesquisador na área de educação em Química tem como interesse uma variedade de questões básicas, que servem a dois públicos diferentes: aqueles que querem entender os problemas envolvidos em ensinar e aprender Química e aqueles que querem saber mais acerca de como tal conhecimento é efetivado. Muitos profissionais atuam em mais de uma área, fazendo com que haja uma interação entre estes ramos ${ }^{1}$. Para "ensinar" química pode-se lançar mão de várias ferramentas: aulas teóricas, aulas experimentais, participação na pesquisa básica (teórica e/ou experimental), programas de computação, jogos, etc. Uma das ferramentas que traz muitos benefícios aos alunos é a participação em experimentos de laboratório, pois é uma maneira mais "concreta" de se entrar em contato com a teoria ensinada na sala de aula.

No caso específico de experimentos para laboratórios de química orgânica, Mohrig ${ }^{2}$ ressalta que os experimentos ainda são executados em laboratório na forma "receita de bolo", onde o aluno simplesmente é levado ao "faça isto, faça aquilo e verifique isto". Muitos são os autores ${ }^{3-7}$ interessados em elaborar experimentos mais atuais e motivadores, utilizando maneiras diferentes de tratamentos e interpretações de resultados. Mas um curso de licenciatura em Química no período noturno, ainda enfrenta o problema do curto espaço de tempo ( 3 a 4 h) reservado para uma prática de laboratório.

Em conjunto com os experimentos tradicionais da química orgânica, a inserção de experimentos rápidos, de fácil compreensão e próximos do cotidiano, mesmo sendo multidisciplinares, pode proporcionar ao aluno maior participação e maior reflexão sobre aquilo que ele está fazendo em laboratório.

Este trabalho tem a intenção de contribuir para a elaboração

*e-mail: dmafn@ufpe.br deste tipo de experimento, introduzindo técnicas ou metodologias atuais na área da química voltada para o nível universitário. Assim sendo, alguns experimentos desenvolvidos nos laboratórios de pesquisa do Departamento de Química Fundamental da Universidade Federal de Pernambuco foram adaptados para que possam ser realizados nos laboratórios de ensino da graduação. Durante o curso de Química Orgânica Experimental de 2002, introduzimos três novos experimentos envolvendo as seguintes áreas do conhecimento: eletrossíntese orgânica (hidrogenação de compostos orgânicos insaturados $)^{8}$, extração de voláteis do aroma do abacaxi ("headspace" dinâmico) ${ }^{9}$ e síntese orgânica no estado sólido utilizando microondas (química ambiental) ${ }^{10}$. A seguir, procuramos mostrar a importância da introdução destes experimentos na graduação.

A química orgânica moderna procura pesquisar reações que sejam mais eficientes, seletivas, menos poluentes e que possam ser realizadas em condições simples de trabalho, melhorando os processos de síntese já conhecidos ${ }^{8}$. A eletrossíntese tem sido muito empregada em vários processos industriais, como por ex., a síntese da adiponitrila ${ }^{11}$, utilizada na preparação de polímeros e a síntese de soda e cloro $^{12}$. A hidrogenação catalítica é muito utilizada nas indústrias petroquímica, alimentícia e farmacêutica; mas neste caso, a utilização de uma fonte de gás hidrogênio permanente inspira cuidados. A principal vantagem da hidrogenação eletrocatalítica é a utilização de elétrons para produção de hidrogênio in situ, cuja passagem controlada de carga permite o controle da seletividade do processo, com baixo custo ${ }^{13}$.

A "Química Verde" tornou-se uma área da química aliada à saúde humana, sem perder o desenvolvimento necessário, por isso sua prática vem sendo incentivada pela academia de pesquisa, indústria e governo. Ela apresenta doze princípios ${ }^{14}$ básicos, os quais visam o desenvolvimento de processos livres de solventes. Procura-se também evitar a formação de compostos secundários danosos à saúde e ao meio ambiente, maximizando o aproveitamento dos reagentes de maneira rápida. Uma outra tentativa é a minimização de qualquer tipo de acidente possível, em processos que sejam de baixo custo, tanto em micro como em macro-escala. Reed e Hutchison ${ }^{6}$ expuseram a preocupação com a inclusão de experimentos em "Química Verde" no laboratório de graduação, 
como uma forma de colaborar na abordagem de conceitos teóricos que permeiam esta crescente área de pesquisa na química orgânica. Estes autores adaptaram a síntese de ácido adípico (ácido 1,6hexanodióico) a partir da oxidação catalítica do ciclo-hexeno em meio aquoso, onde a mistura catalítica aquosa pode ser reciclada ao invés de se transformar em rejeito. Em 1977, Arruda e Santelli ${ }^{15}$ relataram o emprego de microondas como fonte de energia para mecanização de amostras. Este processo foi apresentado como alternativa aos processos convencionais, uma vez que reduz o tempo de preparo de amostras e os problemas associados à perda de componentes voláteis e contaminações.

O tópico sobre substâncias orgânicas gustativas e odoríferas tem sido freqüentemente considerado no curso de Química. O trabalho de Hodgson et al. ${ }^{7}$ descreve as propriedades organolépticas de desodorantes, balas, compostos provenientes da degradação de peixe, frutas, perfumes, flores, análise de água, etc., sendo estes de grande aplicação em indústrias alimentícias e de perfumaria. Segundo os autores ${ }^{7}$, são poucos os experimentos desenvolvidos nesta área para laboratórios da graduação, portanto, elaboraram um experimento de "headspace" dinâmico, proporcionando isolamento e análise de compostos orgânicos voláteis (COVs) por cromatografia gasosa acoplada à espectrometria de massas (CG-EM), presentes em bolas de polietileno de baixa densidade.

Cada um dos experimentos elaborados, neste trabalho, visa a introdução de conteúdos tradicionais aliados a conteúdos não-convencionais, mostrando a multidisciplinaridade presente na química orgânica atual, que é de considerável importância dentro da química laboratorial moderna.

\section{DESCRIÇÃO DOS EXPERIMENTOS}

\section{Hidrogenação eletrocatalítica (HEC) do benzaldeído ${ }^{8}$}

Os resultados obtidos na redução de olefinas conjugadas (2ciclo-hexen-1-ona, benzaldeído, acetofenonas, estireno, etc) demonstraram que o método de HEC em cela unitária utilizando ânodo de sacrifício (Esquema 1) pode proporcionar seletividade aliada a excelentes rendimentos $(88-95 \%)$ e boa eficiência eletroquímica $(50-80 \%)^{16,17}$.

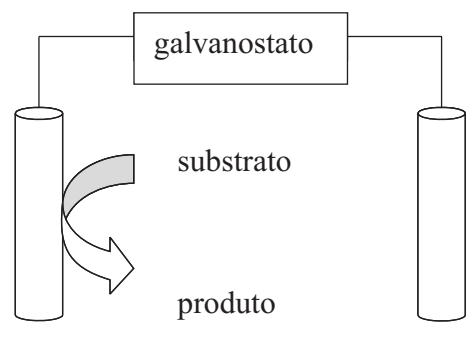

$\mathrm{Fe}$

$\mathrm{Ni}$

Esquema 1. Representação do sistema para HEC utilizando ânodo de sacrificio de $\mathrm{Ni}$

O sucesso da HEC está associado à conjugação de dois mecanismos: o de geração de hidrogênio e o de hidrogenação catalítica ${ }^{16}$. O primeiro processo, também chamado de reação de evolução de hidrogênio (REH), está classicamente baseado na etapa de descarga elétrica primária, gerando o hidrogênio atômico que permanece na superfície do metal por adsorção química:

$\mathrm{H}^{+}{ }_{(\mathrm{aq})}+\mathrm{e}-\longrightarrow \mathrm{H}_{(\text {ad) }}^{\cdot}$

(1) Etapa de Volmer
A etapa seguinte pode ser tanto a reação de recombinação de $\mathrm{H}^{*}$<smiles>[11NH2+][15NH2]</smiles>

(2) Etapa de Tafel

como a reação entre um próton, um átomo de hidrogênio e um elétron (desorção eletroquímica)

$\mathrm{H}_{(\mathrm{ad})}^{\cdot}+\mathrm{H}_{(\mathrm{aq})}^{+}+\mathrm{e}-\longrightarrow \mathrm{H}_{2}$

(3) Etapa de Heyrovsky

Segundo o mecanismo de redução descrito acima, somente a etapa de Volmer gera $\mathrm{o}^{\cdot}{ }_{(\mathrm{ad})}$ necessário para hidrogenação do substrato orgânico, as outras duas etapas geram hidrogênio molecular, que é perdido na forma de gás, diminuindo a eficiência eletroquímica do processo ${ }^{16}$.

O processo de HEC estará completo após outras três etapas ${ }^{16}$, características para a reação de hidrogenação catalítica (HC), em outras palavras: adsorção da olefina na superfície do metal (4), hidrogenação da olefina (5) e desorção do produto hidrogenado da superfície do eletrodo (6):
$\mathrm{Y}=\mathrm{Z} \stackrel{\mathrm{M}}{\longrightarrow}(\mathrm{Y}=\mathrm{Z})_{(\text {ad. })}$
(4) Adsorção
$(\mathrm{Y}=\mathrm{Z})_{(\text {ad. })}+2 \mathrm{H}^{\cdot} \stackrel{\mathrm{M}}{\longrightarrow}(\mathrm{YH}-\mathrm{ZH})_{(\text {ad. })}$
(5) Hidrogenação
$(\mathrm{YH}-\mathrm{ZH})_{(\text {ad.) }} \stackrel{\mathrm{M}}{\longrightarrow}(\mathrm{YH}-\mathrm{ZH})$
(6) Desorção

Todo este processo depende do material do cátodo (M), uma vez que o mesmo possui dupla função, como gerador de hidrogênio atômico e catalisador ${ }^{16}$.

\section{Parte experimental}

Soluções

Transferir $40 \mathrm{~mL}$ de solução de cloreto de amônio (0,25 M) para o interior do frasco da célula eletrolítica (Figura 1), seguidos de $10 \mathrm{~mL}$ de uma solução metanólica de benzaldeído $(0,5 \mathrm{mmol})$.

\section{Montagem da célula eletrolítica}

Inicialmente, a placa de níquel ( 3 × 2 × 0,5 cm) deve ser limpa através da rápida imersão em solução aquosa de ácido clorídrico (1:1), seguida da lavagem com água destilada para remoção do ácido e passando por uma solução de acetona para secagem. A barra de ferro (10 cm de altura e $1 \mathrm{~cm}$ de diâmetro) deve ser polida com lixas número 450, para remover todas as partes oxidadas. Em um frasco de vidro, com tampa de dois orifícios, posicionar os eletrodos de níquel e de ferro. Conectar os eletrodos a uma fonte de $1,5 \mathrm{~V}$ (pilha), onde o eletrodo de níquel é o pólo positivo e o de ferro é o pólo negativo (devem ser utilizados fios de cobre e "jaca-

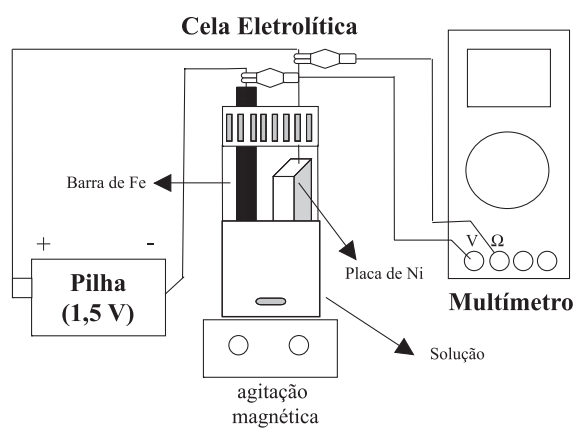

Figura 1. Montagem do sistema de hidrogenação eletrocatalítica 
rés"). O sistema deve estar acoplado a um multímetro, para monitoramento do potencial (Figura 1). A eletrocatálise deve ser realizada sob agitação magnética. A hidrogenação estará concluída em $3 \mathrm{~h}$. O potencial deve ser controlado pelo multímetro, marcando entre 1,5 e $1,4 \mathrm{~V}$ até o término do experimento.

\section{Extração}

Transferir $2 \mathrm{~mL}$ do meio reacional para um tubo de ensaio e adicionar $1 \mathrm{~mL}$ de éter etílico + anisol (em concentração próxima à do produto obtido); agitar vigorosamente. Deixar o tubo de ensaio contendo solução aquosa + éter em repouso por $5 \mathrm{~min}$.

\section{Análise rápida}

Retirar uma alíquota de $1 \mu \mathrm{L}$ da fase etérea e injetar no cromatógrafo gasoso. O anisol é utilizado como padrão interno para quantificar o produto. Confirmar a presença do produto hidrogenado por co-injeção no cromatógrafo gasoso ${ }^{8}$, com amostra padrão, Esquema 2.

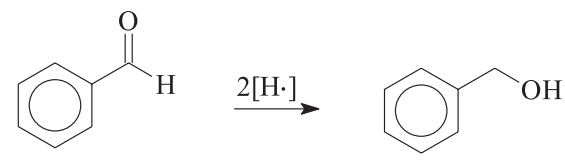

Esquema 2. Reação de HEC do benzaldeído

\section{Análise tradicional}

Realizar o processo de extração do produto do meio reacional com éter etílico ( $3 \times 10 \mathrm{~mL}$ ) em funil de separação, secar a fase etérea com sulfato de magnésio anidro, evaporar o éter e providenciar os espectros de IV, RMN de ${ }^{1} \mathrm{H}$ e de ${ }^{13} \mathrm{C}$.

\section{Assuntos abordados na prática}

Hidrogenação catalítica (comparar com a química tradicional vantagens e desvantagens), sistema eletroquímico, extração líquido-líquido e cromatografia gasosa (qualitativa e quantitativa (padrão interno)) ou espectroscopia na região do infravermelho, ressonância magnética nuclear de hidrogênio e de carbono-13.

\section{Extração de voláteis do abacaxi pelo método de " headspace" dinâmico (HD)}

A utilização de experimentos de análise de compostos orgâni$\cos$ voláteis (COVs) vem sendo incentivada por alguns autores ${ }^{7,18}$ para efetuar a introdução de cromatografia gasosa acoplada à espectrometria de massas (CG/MS), na química orgânica experimental da graduação. Deste modo, foi feita a adaptação de um experimento envolvendo análise por "headspace" dinâmico dos voláteis do aroma do abacaxi (Ananas comosus).

A técnica de análise por "headspace" é muito utilizada na préconcentração de compostos voláteis em baixas concentrações, provenientes de uma matriz ${ }^{19,20}$ : contaminantes em água, análise de aroma de alimentos ${ }^{21}$, fluidos biológicos, odores humanos, ecologia química ${ }^{22}$, etc.

A análise por "headspace" dinâmico (AHD) é um método contínuo de extração que vai retirando os compostos voláteis da matriz. A análise por "headspace" estático requer um rígido controle da temperatura no processo e a concentração dos analitos nas fases não muda com o passar do tempo, depois do sistema ter alcançado o equilíbrio entre as fases ${ }^{20}$. Os tubos contendo as fases estacionárias (adsorvente), que retem os compostos orgânicos, funcionam aproximadamente como uma coluna cromatográfica contendo uma mistura de concentração constante. Esta coluna possui limite de adsorção de analitos; quando o volume inerte do gás de arraste que passa pelo tubo adsorvente se igualar ao volume retido do analito à temperatura $\mathrm{T}$, as forças intermoleculares são rompidas e ele é eluído da coluna. Assim sendo, é importante saber quais são os volumes limites de cada analito, para saber quando da ocorrência da extração completa destes no adsorvente. Para se conhecer estes volumes limites de retenção, os seguintes parâmetros devem ser avaliados: forma e tamanho da coluna adsorvente; quantidade e inércia dos analitos; porosidade e área superficial específica do adsorvente; fluxo, pureza e temperatura do gás inerte utilizado e, concentração original, estrutura química dos analitos na amostra e complexidade da mistura. O volume máximo de amostra (V), que pode ser introduzido através da coluna adsorvente, sem se ultrapassar o limite de adsorção, é dado pela equação

$\mathrm{V}=\mathrm{V}_{\mathrm{R}}^{i}(1-2 / \sqrt{\mathrm{N}})$

onde, $\mathrm{N}$ é o número de pratos teóricos da coluna adsorvente e $\mathrm{V}_{\mathrm{R}}^{i}$ é o volume de retenção do analito $i$.

É importante ter em mente que cada adsorvente utilizado para pré-concentrar COVs deve ser escolhido conforme o tipo de matriz e/ou os compostos que se tem interesse em isolar ${ }^{19}$.

\section{Parte experimental}

Um abacaxi maduro (sem a coroa, $\sim 1,3 \mathrm{~kg}$ ) deve ser picado em pequenos cubos $(3 \mathrm{~cm})$ e aerados por $2 \mathrm{~h}$, utilizando-se um recipiente de vidro com capacidade para $2 \mathrm{~L}$, permitindo a passagem do ar atmosférico previamente seco, Figura 2.

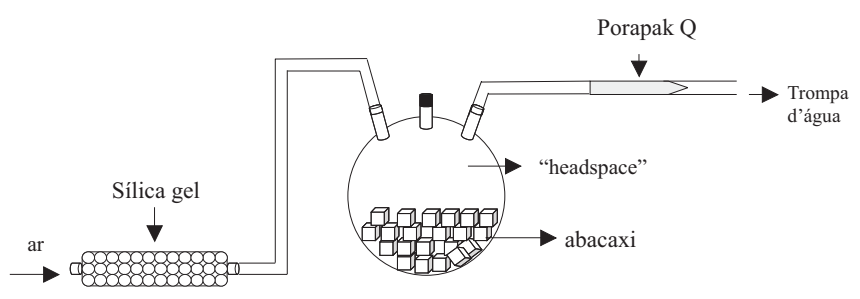

Figura 2. Aparatos da extração dos voláteis do abacaxi utilizando a metodologia de $H D$

O ar e os voláteis liberados pelos pedaços do fruto serão arrastados pelo vácuo, proporcionado por uma trompa d'água, e aprisionados em tubo contendo um adsorvente $(0,25 \mathrm{~g}$ de Porapak Q (etilvinilbenzeno/divinilbenzeno, 50-80 mesh). O tubo adsorvente será removido do sistema e os constituintes voláteis serão dessorvidos do adsorvente com 1,70 mL de hexano destilado. Após a obtenção deste extrato hexânico, os alunos deverão injetar $1 \mu \mathrm{L}$ do extrato no cromatógrafo gasoso e averiguar a presença de 3 voláteis prioritários: hexanoato de metila (a), hexanoato de etila (b), e octanoato de metila (c), Figura 3. A amostra deve ser encaminhada para análise por cromatografia gasosa acoplada à espectrometria de massa e os espectros de massas de baixa resolução destes 3 compostos deverão ser fornecidos aos alunos, para que possam analisar e apresentar ao professor o modelo de fragmentação observado nos espectros e as prováveis estruturas iônicas dos três compostos. São eles (Figura 4): hexanoato de metila $(\mathrm{m} / \mathrm{z}$ ) 130(1), 99(20), 87(33), 74(100), 59(17); hexanoato de etila $(\mathrm{m} / \mathrm{z})$ 99(47), 88(100), 70(36); octanoato de metila $(\mathrm{m} / \mathrm{z})$ 127(8), 87(36), 74(100), 59(18). Na Figura 4 exemplifica-se o espectro de massas característico de um éster graxo isolado no experimento (hexanoato de metila) e suas fragmentações (Esquema 3). 


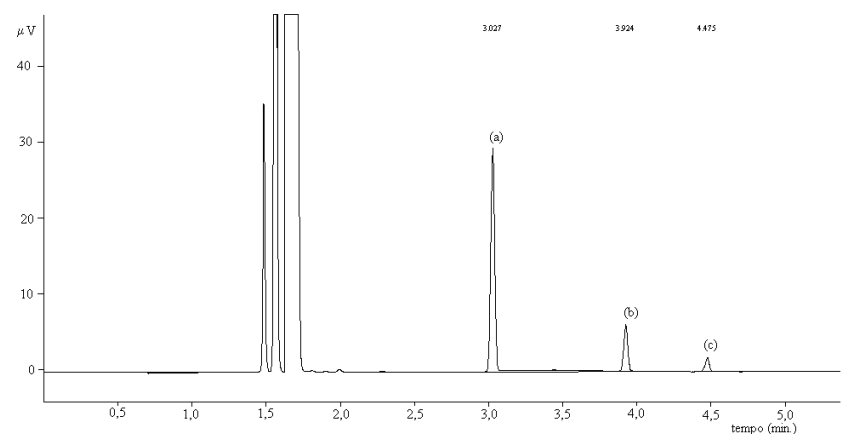

Figura 3. Cromatograma gasoso do extrato n-hexânico dos voláteis do aroma do abacaxi obtido por HD: hexanoato de metila (a), hexanoato de etila $(b) e$ octanoato de metila (c)

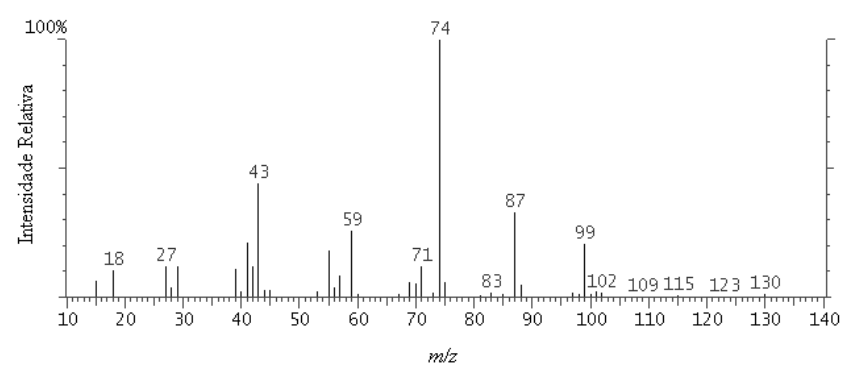

Figura 4. Espectro de massas do hexanoato de metila

Assuntos abordados na prática

Teoria de extração de compostos voláteis e não-voláteis, "headspace", produtos naturais e cromatografia gasosa qualitativa e quantitativa (normalização e padrão interno).

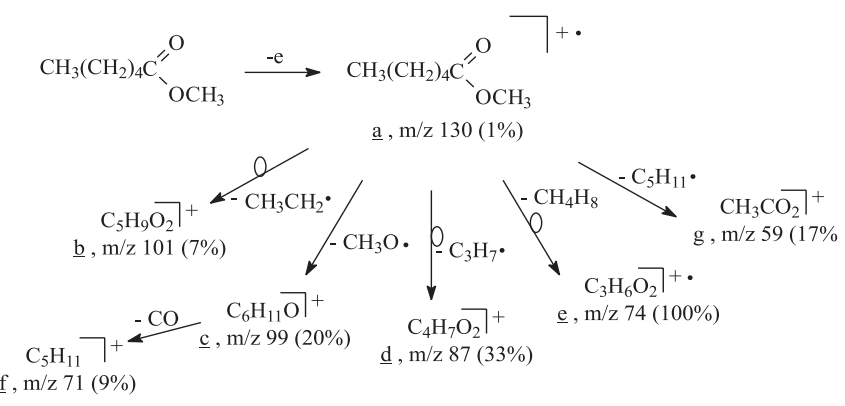

Esquema 3. Modelo de fragmentação do hexanoato de metila

\section{Síntese de ácidos $\mathrm{N}$-arilftalâmicos utilizando forno de microondas doméstico (Química Verde)}

Nos últimos dezoito anos, a aplicação da irradiação de microondas (MO) tem sido freqüentemente utilizada em reações de síntese de compostos orgânicos ${ }^{23}$ e, recentemente, foi relatada a síntese dos ácidos $N$-arilftalâmicos a partir do anidrido ftálico e aminas aromáticas $^{24}$.

A principal vantagem desta técnica é o rápido aquecimento das moléculas presentes na mistura, pois este processo não depende da condutividade térmica dos materiais e sim da rotação de dipolo, ou seja, interação na qual moléculas polares tentam se alinhar mudando rapidamente com o campo elétrico das microondas ou condução iônica; neste caso, a transferência de energia ocorre se existirem espécies iônicas ou íons livres no meio sendo aquecidas ${ }^{23}$. Além disto, as reações realizadas em forno de microondas são limpas, eficientes, mais seletivas, menos dispendiosas e com excelentes rendimentos.

Tendo como base a viabilidade dessas reações, implementamos a síntese de compostos orgânicos utilizando um forno de microondas doméstico, como prática rotineira para alunos de graduação, nos laboratórios de química orgânica experimental.

De um modo geral, os ácidos $N$-arilftalâmicos são obtidos como intermediários na síntese de $N$-arilftalimidas pela condensação de anidrido ftálico e aminas primárias ou secundárias sob refluxo à baixa temperatura ${ }^{25}$, ou pela hidrólise parcial de ftalimidas $N$-substituídas em meio básico ${ }^{25,26}$. Este experimento, síntese do ácido $p$ clorofenilftalimida (Esquema 4), mostra uma reação rápida e eficiente entre dois sólidos que se fundem fornecendo um líquido, que é mais propenso a absorver microondas, em que a reação ocorre após fusão e solubilização do anidrido ftálico nas aminas.

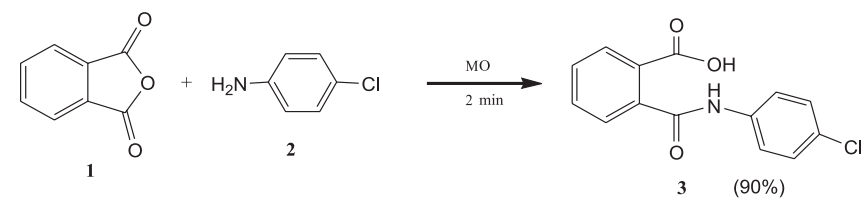

Esquema 4. Reação em microondas para obtenção do ácido N-pclorofenilftalâmico

\section{Parte experimental}

Transferir para uma cápsula de porcelana $200 \mathrm{mg}(1,35 \mathrm{mmol})$ anidrido ftálico e $172 \mathrm{mg}(1,35 \mathrm{mmol})$ de $p$-cloroanilina e macerar bem. Levar a mistura ao forno de micoondas por 2 min à potência máxima (650W). Depois de retirar do forno, adicionar a essa mistura aproximadamente $3 \mathrm{~mL}$ de acetona, transferí-la a um erlemmeyer e aquecer para solubilizar o conteúdo. Após deixar esfriar à temperatura ambiente, observar a formação de cristais finos e pequenos, em forma de agulhas, e filtrar. Tirar o ponto de fusão desses cristais que deve estar entre 194 a $196{ }^{\circ} \mathrm{C}$. O rendimento obtido deve ser em torno de $95 \%$. A formação do produto poderá ser visualizada na placa de cromatografia em camada delgada (CCD) sob luz ultravioleta (Figura 5), na qual deverão ser aplicados anidrido ftálico, $p$-cloroanilina, o produto e a mistura dos reagentes e produto. O solvente para realizar CCD pode ser uma mistura de clorofórmio e acetato de etila $(1,5: 1,0)$. A revelação das manchas na placa cromatográfica deverá ser observada em luz UV (254 nm).

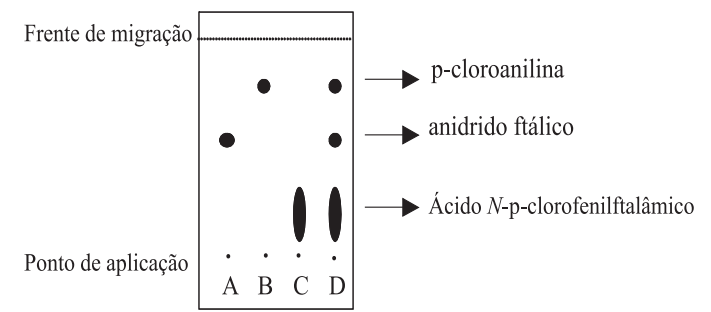

Figura 5. Placa de cromatografia em camada delgada

Assuntos abordados na prática

Síntese orgânica em microondas, cristalização, ponto de fusão, cromatografia em camada delgada, IV, RMN de ${ }^{1} \mathrm{H}$ e de ${ }^{13} \mathrm{C}$.

\section{CONSIDERAÇÕES GERAIS}

Os experimentos descritos possibilitarão aos alunos identificar os produtos finais, utilizando técnicas básicas de análise (CG/EM, 
IV, RMN de ${ }^{1} \mathrm{H}$ e de ${ }^{13} \mathrm{C}$ ). A confirmação das estruturas dos compostos deverá ser feita através da avaliação dos dados obtidos nos respectivos espectros do(s) composto(s) analisado(s). Os experimentos propostos visam a concretização de diversos conceitos em diferentes áreas da química, tendo sido adaptados para serem desenvolvidos em curto espaço de tempo $(4 \mathrm{~h})$, respeitando os limites de um experimento desenvolvido para laboratório de graduação da licenciatura, no período noturno.

\section{AGRADECIMENTOS}

Ao CNPq, à CAPES e FINEP pelo apoio financeiro.

\section{REFERÊNCIAS}

1. Bunce, D. M.; Robinson, W. R.; J. Chem. Educ. 1997, 74, 1076.

2. Mohrig, J. R.; J. Chem. Educ. 2004, 81, 1083.

3. Cunha, S.; Lião, L. M.; Bomfim, R. R.; Bastos, R. M.; Monteiro, A. P. M.; Alencar, K. S.; Quim. Nova 2003, 26, 425.

4. Brenelli, E. C. S.; Quim. Nova 2003, 26, 136.

5. Leite, O. D. L.; Fatibello-Filho, O.; Rocha, F. R. P.; Quim. Nova 2004, 27, 337.

6. Reed S. M.; Hutchison, J. E.; J. Chem. Educ. 2000, 77, 1627.

7. Hodgson, S. C.; Casey, R. J.; Orbell, J. D.; Bigger, S. W.; J. Chem. Educ. 2000, 77, 1631

8. Navarro, D. M. A. F.; Navarro, M.; J. Chem. Educ. 2004, 81, 1350.
9. Navarro, D. M. A. F.; Murta, M. M.; Duarte, A. G.; Lima, I. S.; Nascimento, R. R.; Sant'Ana, A. E. G.; Quim. Nova 2002, 25, 32. Duarte, A. G.; Navarro, D. M. A. F.; Sant' Ana, A. E. G.; Lima, I. S.; Rev. Bras. Frutic. 2003, 25, 81 .

10. Deshayes, S.; Liagre, M.; Loupy, A.; Luche, J. L.; Petit, A.; Tetrahedron 1999, 55, 10851

11. Alkire, R. C.; J. Chem. Educ. 1983, 60, 274.

12. Wagenknecht, J. H.; J. Chem. Educ. 1983, 60, 271.

13. Navarro, D. M. A. F.; Navarro, M.; Quim. Nova 2004, 27, 301.

14. Hjeresen, D. L.; Schutt, D. L.; Boese, J. M.; J. Chem. Educ. 2000, 77, 1543; Lenardão, E. J.; Freitag, R. A.; Dabdoub, M. J.; Batista, A. C. F.; Silveira, C. da. C.; Quim. Nova 2003, 26, 123.

15. Arruda, M. A. Z.; Santelli, R. E.; Quim. Nova 1997, 20, 638.

16. Santana, D. S.; Melo, G. O.; Lima, M. V. F.; Daniel, J. R. R.; Areias, M. C. C.; Navarro, M.; J. Electroanal. Chem. 2004, 569, 71

17. Santana, D. S.; Lima, M. V. F.; Daniel, J. R. R.; Navarro, M.; Tetrahedron Lett. 2003, 44, 4725.

18. Knupp, G.; Kusch, P.; Neugebauer, M.; J. Chem. Educ. 2002, 79, 98.

19. Núñez, A. J.; González, L. F.; J. Chromatogr. 1984, 300, 127.

20. Gobato, E. A. A. F.; Lanças, F. M.; Quim. Nova 2001, 24, 176.

21. Wilkes, J. G.; Conte, E. D.; Kim, Y.; Holcomb, M.; Sutherland, J. B.; Miller, D. W.; J. Chromatogr., A 2000, 880, 3.

22. Agelopoulos, N. G.; Pickett, J. A.; J. Chem. Ecol. 1998, 24, 1161.

23. Hayes, B. L.; Microwave Synthesis. Chemistry at the Speed of Light, Book News: Portland, 2002, p. 11-27.

24. Sena, V. L. M.; Srivastava, R. M.; Oliveira, S. P.; Lima, V. L. O.; Bioorg. Med. Chem. Lett. 2001, 11, 2671

25. Van der Müllen, P. H.; Rec. Trav. Chim. 1986, 15, 282.

26. Lley, J.; Calheiros, T.; Moreira, R.; Bioorg. Med. Chem. Lett. 1998, 8, 955. 